\title{
Natural orifice translumenal endoscopic surgery (NOTES): What are we getting into?
}

\author{
Lawrence C Hookey $\mathrm{MD}^{1}$, Randy Ellis $\mathrm{PhD}^{2}$
}

\section{WHAT IS NATURAL ORIFICE TRANSLUMENAL ENDOSCOPIC SURGERY?}

For most gastroenterologists, one of the first rules of endoscopy is to diligently avoid perforation of the gastrointestinal lumen. While this principle remains true in the majority of cases, therapeutic crossing of the gastric or duodenal lumen is now accepted for pancreatic pseudocyst drainage and percutaneous gastrostomy tube placement. Endoscopic ultrasound-guided fine needle aspiration of abnormalities in the abdomen and mediastinum has further pushed this barrier. Natural orifice translumenal endoscopic surgery (NOTES), first described in 2004 (1), extends the concept of extraluminal endoscopic intervention to another level. The technique begins with the creation of an opening in a natural lumen (most often gastric, although colonic, vesical, vaginal and uterine approaches have been described) using either electrosurgical incision or needle puncture followed by balloon dilation. An endoscope is then passed through the opening, with pneumoperitoneum provided through the endoscope. Procedures such as cholecystectomy and oophorectomy are performed using traditional (snares, biopsy forceps, endo-loops) and nontraditional (endoscopic suturing devices) endoscopic equipment. Upon withdrawal of the endoscope back into the lumen, the wall defect is closed using clips or sutures. Although most work has been limited to animal experiments (most commonly pigs), Drs Reddy and Rao, from the Asian Institute of Gastroenterology in Hyderabad, India, have performed a limited number of transgastric appendectomies in humans (personal communication).

The main potential advantages of NOTES are related to the lack of transabdominal incisions. This could possibly reduce anesthetic requirements and postoperative pain, leading to faster recovery. The lack of restricted inspiration secondary to abdominal wall pain could potentially lead to a lower rate of postoperative atelectasis and pneumonia. In addition, patients who traditionally have poorer outcomes with open surgery (those with chronic obstructive pulmonary disease, the morbidly obese, corticosteroid users) may be particularly suited to NOTES, with its potential for easier access to the peritoneum and decreased postoperative recovery. The cosmetic advantage of NOTES, or 'scarless surgery', is obvious. However, the importance of this is still debated (2) and the significance that patients would place on this remains to be determined.

\section{MAIN CHALLENGES}

The field of NOTES is evolving at a rapid pace but substantial challenges still exist before its translation to use in humans can be considered. Infection remains a primary concern. For transgastric procedures, the instruments are passed through the mouth, with its multitude of organisms, and then through the stomach into a sterile field - the peritoneum. Overtubes and gastric lavage with antibiotic solutions have been used in an attempt to reduce infection rates, but their efficacy has yet to be clarified $(3,4)$.

While in the peritoneum, orientation can be a challenge, because the triangulation used by surgeons during laparoscopy is not possible. Some organs appear relatively easy to find, such as the uterus and ovaries, while others are somewhat surprisingly difficult to localize (gallbladder, spleen) (5). Potential solutions may involve spatial orientation devices, or preoperative computed tomography scans with realtime reconstruction imaging. The flexibility of the endoscope, usually its advantage, can lead to difficulties during intraperitoneal procedures. Another problem encountered in early studies is control of the intraperitoneal pressure from insufflation, which in some cases has become too high and decreased perfusion to vital organs, requiring decompression via a transabdominal needle. However, the biggest challenge thus far is consistent, safe closure of the defect in the lumen wall. Accordingly, this is also one the most intense areas of research and development. Several techniques have been developed and are being assessed currently, using various methods of clips and sutures $(1,4-7)$.

\section{FIELDS OF INTEREST/INDICATIONS}

Numerous surgeries have been performed via NOTES, including cholecystectomy, oophorectomy, hysterectomy, splenectomy, appendectomy and gastrojejunostomy. Most of these have thus far been feasibility studies, without a true view at comparing outcomes, but research is now moving in that direction, with survival studies being reported and randomized trials starting soon. In 2005, a working group involving the American Society of Gastrointestinal Endoscopy and the

\footnotetext{
${ }^{1}$ Division of Gastroenterology; ${ }^{2}$ School of Computing, Department of Mechanical and Materials Engineering, Department of Surgery, Hotel Dieu Hospital, Kingston, Ontario

Correspondence: Dr Lawrence C Hookey, Queen's University, Division of Gastroenterology, Hotel Dieu Hospital, 166 Brock Street, Kingston, Ontario K7L 5G2. Telephone 613-544-3310, fax 613-544-3114, e-mail hookeyl@hdh.kari.net
} 
Society of American Gastrointestinal Endoscopic Surgeons was created to discuss NOTES, to share experiences and to develop a plan for future research. This group, named the Natural Orifice Surgery Consortium for Assessment and Research, produced a white paper identifying critical areas to be resolved with future research (5). The group also highlighted the need for a multidisciplinary approach to this field, including members with laparoscopic expertise (surgeons) and flexible endoscopy expertise (gastroenterologists). In addition, the working group agreed that all members would limit research to animal models, ie, no human studies, until certain agreed upon standards are met, and that all subsequent human procedures be performed under the approval of institutional research ethics boards, as well as placed in a central registry. This working group now has regular research meetings and has adopted the acronym NOSCAR. The organization has established a competitive grant award system and recently awarded nearly one million dollars in research funding.

\section{QUEEN'S UNIVERSITY GASTROINTESTINAL DISEASES RESEARCH UNIT (GIDRU) NOTES LABORATORY}

We are in the process of establishing a multidisciplinary NOTES laboratory, which is, to my knowledge, the first in Canada. We have a team of gastroenterologists, general surgeons, gastrointestinal pathologists and a computer science image modeling expert. Our initial goals are to develop a familiarity with the technique of transgastric and transcolonic passage of the endoscope, combined with simple procedures (tubal ligation/oophorectomy, appendectomy). We then plan to focus on specific hypothesis-driven experiments assessing the role of gastric decontamination, various gastric opening and closure techniques, the benefit of preoperative computed tomography with intraoperative computer-assisted positioning (8), and the potential for endoscopic ultrasound to assess lesions beyond the traditional reach of the instrument. We intend to abide by the white paper recommendations (5) and limit our research to ethics board-approved animal experiments until near perfection in these techniques has been obtained.

\section{CONCLUSION}

NOTES is an exciting field that is clearly pushing the boundaries of endoscopy as we know it. Although the procedure in its current form has only moderate benefits over laparoscopic surgery, it is possible that further research will reveal an as yet undiscovered niche. When I speak to surgeons about NOTES, skepticism is frequently expressed but it is always qualified with anecdotes about laparoscopic surgery in the early days; very few people thought it had a role in the future of surgery, yet it has become a mainstay and increasingly more surgeries are being performed using this technique. I believe that skepticism is healthy, and NOTES should be approached in a scientific fashion with an aim to answer questions through hypothesisdriven experiments. Whatever the future of NOTES, current and future research is sure to have the spinoff benefit of advances in intraluminal endoscopy.

\section{REFERENCES}

1. Kalloo AN, Singh VK, Jagannath SB, et al. Flexible transgastric peritoneoscopy: A novel approach to diagnostic and therapeutic interventions in the peritoneal cavity. Gastrointest Endosc 2004;60:114-7.

2. Swain P. A justification for NOTES - Natural orifice translumenal endosurgery. Gastrointest Endosc 2007;65:514-6.

3. Jagannath SB, Kantsevoy SV, Vaughn CA, et al. Peroral transgastric endoscopic ligation of fallopian tubes with long-term survival in a porcine model. Gastrointest Endosc 2005;61:449-53.

4. Merrifield BF, Wagh MS, Thompson CC. Peroral transgastric organ resection: A feasibility study in pigs. Gastrointest Endosc 2006;63:693-7.

5. ASGE, SAGES. ASGE/SAGES Working Group on Natural Orifice Translumenal Endoscopic Surgery White Paper October 2005. Gastrointest Endosc 2006;63:199-203.

6. Kantsevoy SV, Jagannath SB, Niiyama H, et al. Endoscopic gastrojejunostomy with survival in a porcine model. Gastrointest Endosc 2005;62:287-92.

7. Wagh MS, Merrifield BF, Thompson CC. Survival studies after endoscopic transgastric oophorectomy and tubectomy in a porcine model. Gastrointest Endosc 2006;63:473-8.

8. Vosburgh KG, Stylopoulos N, Estepar RS, Ellis RE, Samset E, Thompson CC. EUS with CT improves efficiency and structure identification over conventional EUS. Gastrointest Endosc 2007;65:866-70. 


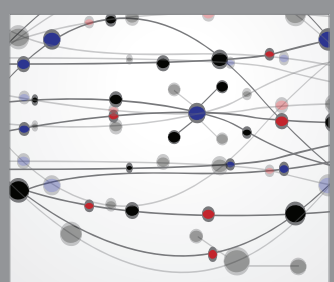

The Scientific World Journal
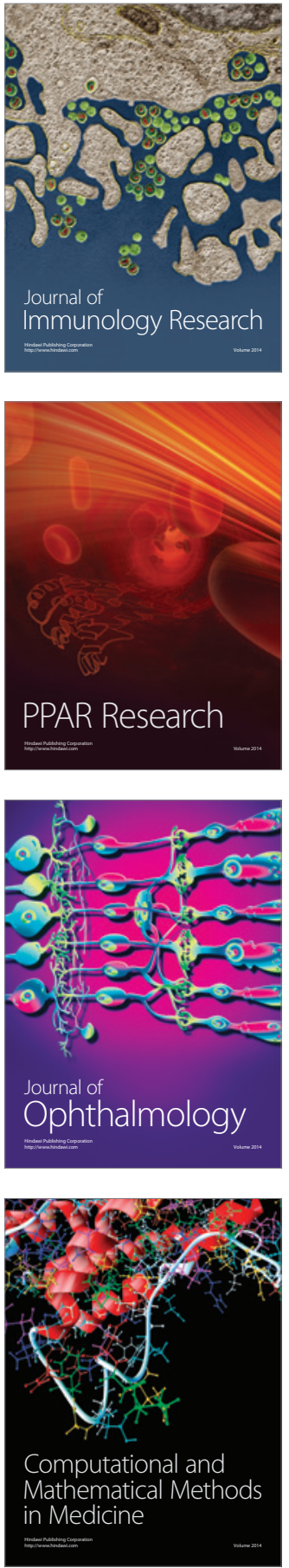

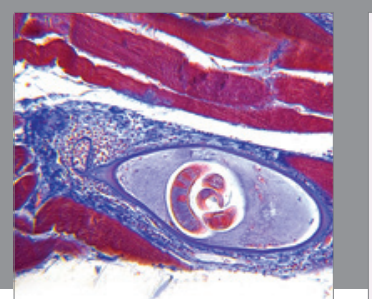

Gastroenterology Research and Practice

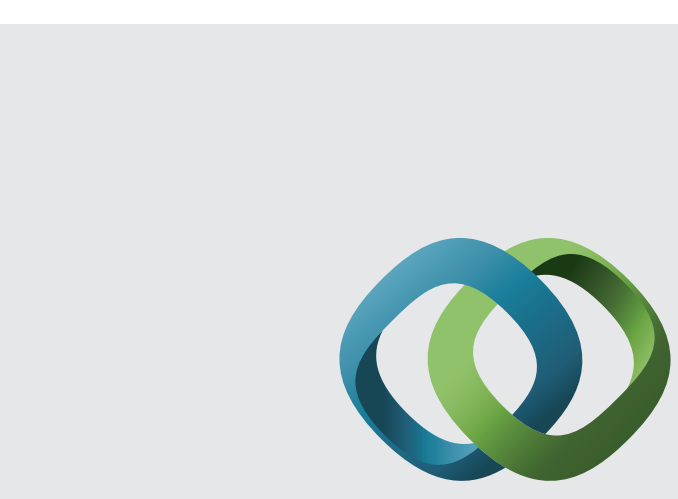

\section{Hindawi}

Submit your manuscripts at

http://www.hindawi.com
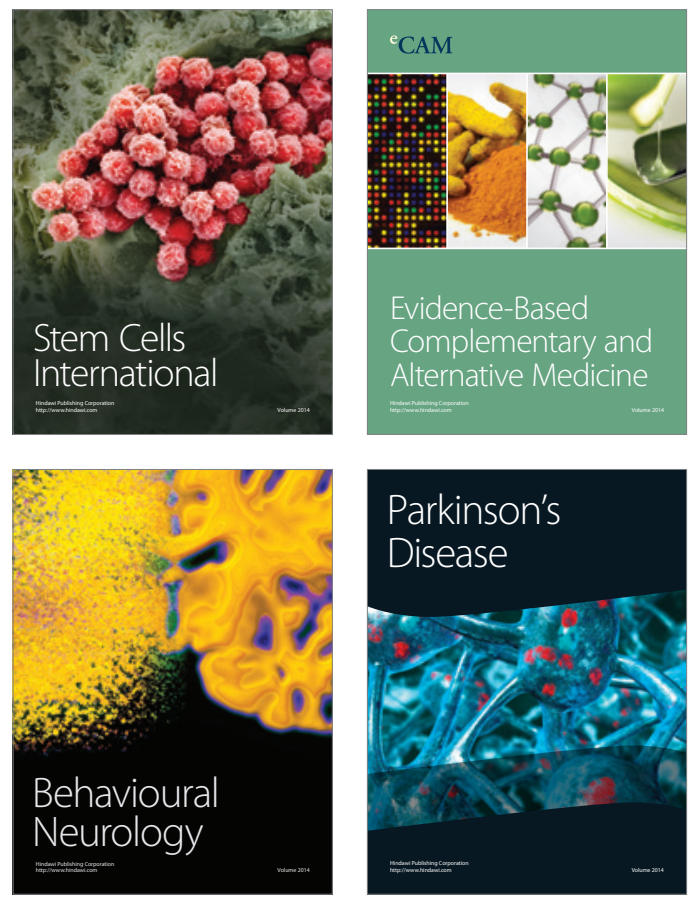
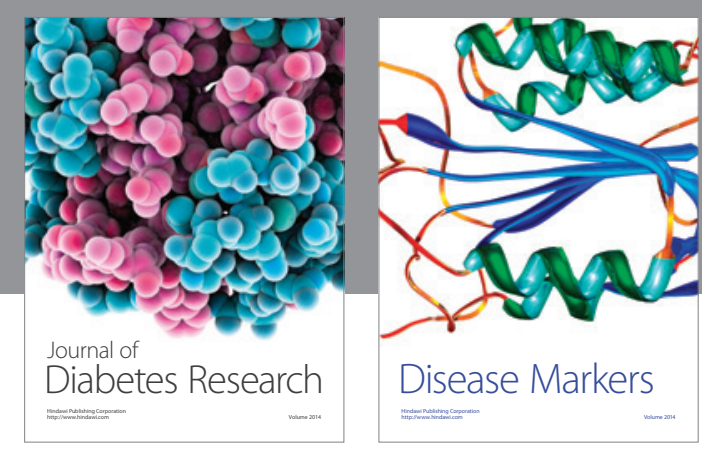

Disease Markers
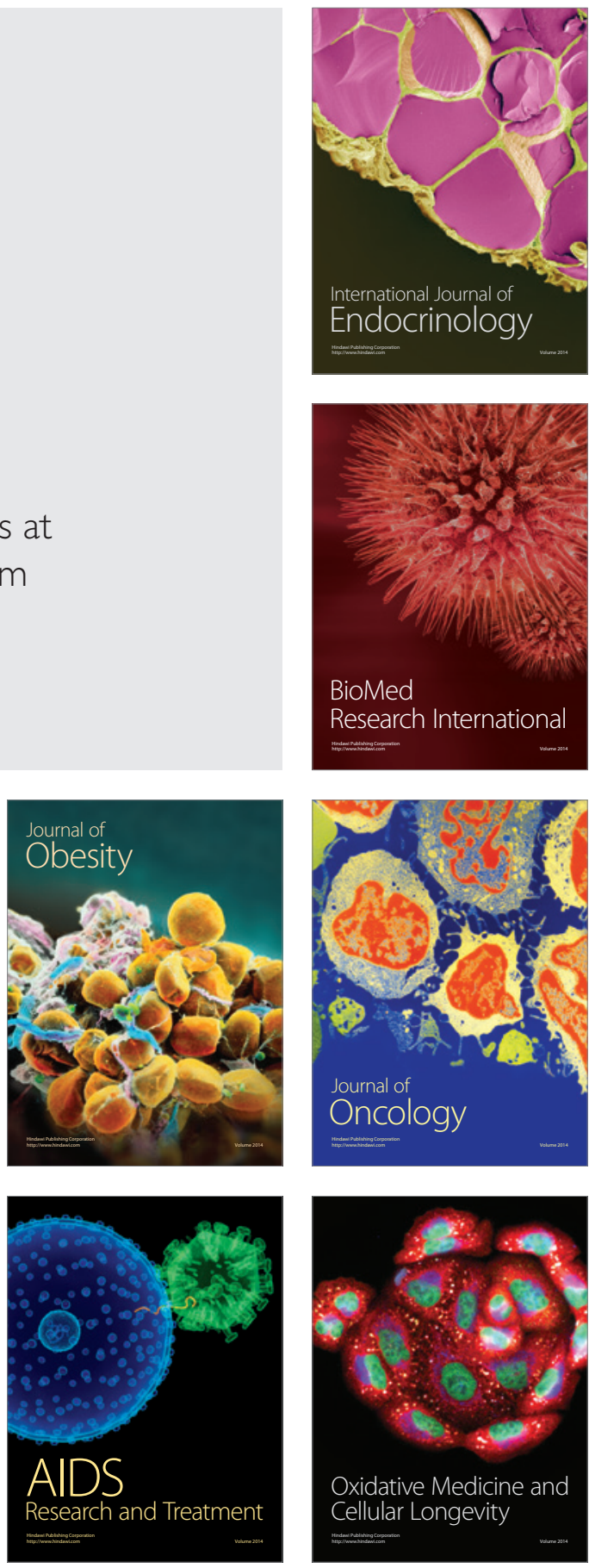